\title{
Educational program in crisis management for cardiac surgery teams including high realism simulation
}

\author{
Louis-Mathieu Stevens, MD, PhD(c), ${ }^{\text {a,b }}$ Jeffrey B. Cooper, $\mathrm{PhD},{ }^{\mathrm{c}, \mathrm{d}}$ Daniel B. Raemer, $\mathrm{PhD},{ }^{\mathrm{c}, \mathrm{d}}$ \\ Robert C. Schneider, MD, ${ }^{\mathrm{c}}$ Allan S. Frankel, MD, ${ }^{\mathrm{e}}$ William R. Berry, MD, MPH, ${ }^{\mathrm{c}}$ and \\ Arvind K. Agnihotri, MD ${ }^{\mathrm{b}}$
}

\begin{abstract}
Introduction: Cardiac surgery demands effective teamwork for safe, high-quality care. The objective of this pilot study was to develop a comprehensive program to sharpen performance of experienced cardiac surgical teams in acute crisis management.
\end{abstract}

\begin{abstract}
Methods: We developed and implemented an educational program for cardiac surgery based on high realism acute crisis simulation scenarios and interactive whole-unit workshop. The impact of these interventions was assessed with postintervention questionnaires, preintervention and 6-month postintervention surveys, and structured interviews.
\end{abstract}

\begin{abstract}
Results: The realism of the acute crisis simulation scenarios gradually improved; most participants rated both the simulation and whole-unit workshop as very good or excellent. Repeat simulation training was recommended every 6 to 12 months by $82 \%$ of the participants. Participants of the interactive workshop identified 2 areas of highest priority: encouraging speaking up about critical information and interprofessional information sharing. They also stressed the importance of briefings, early communication of surgical plan, knowing members of the team, and continued simulation for practice. The pre/post survey response rates were $70 \%(55 / 79)$ and $66 \%$ $(52 / 79)$, respectively. The concept of working as a team improved between surveys $(P=.028)$, with a trend for improvement in gaining common understanding of the plan before a procedure $(P=.075)$ and appropriate resolution of disagreements $(P=.092)$. Interviewees reported that the training had a positive effect on their personal behaviors and patient care, including speaking up more readily and communicating more clearly.
\end{abstract}

Conclusions: Comprehensive team training using simulation and a whole-unit interactive workshop can be successfully deployed for experienced cardiac surgery teams with demonstrable benefits in participant's perception of team performance. (J Thorac Cardiovasc Surg 2012;144:17-24)

Improvements in teamwork among health care professionals have been touted widely as an important element of efforts to reduce adverse outcomes by reducing errors and improving recovery from errors. Educating the workforce to improve teamwork has been adopted in many

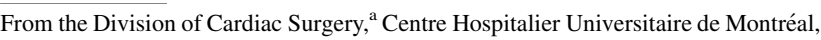
Montreal, Quebec, Canada; Division of Cardiac Surgery ${ }^{\mathrm{b}}$ and Department of Anesthesia, Critical Care and Pain Medicine, ${ }^{c}$ Massachusetts General Hospital, Harvard Medical School, Boston, Mass; Center for Medical Simulation, ${ }^{\mathrm{d}}$ Cambridge, Mass; and Pascal Metrics, ${ }^{e}$ Washington, DC.

This study was supported by an unrestricted grant from CRICO/Risk Management Foundation of the Harvard Medical Institutions. Salary support (to L.M.S.) was provided by a fellowship award from the Canadian Institutes of Health Research's Clinical Research Initiative and the Rossetti Fund (Massachusetts General Hospital, Boston, Massachusetts).

Disclosures: J.B.C. and D.B.R. are faculty and derive salary support from the nonprofit Center for Medical Simulation, which receives income for conducting teamwork training programs for hospital teams such as those involved in this study. All other authors have nothing to disclose with regard to commercial support.

Received for publication Aug 15, 2011; revisions received Dec 6, 2011; accepted for publication March 12, 2012; available ahead of print April 16, 2012.

Address for reprints: Louis-Mathieu Stevens, MD, $\mathrm{PhD}(\mathrm{c})$, Centre Hospitalier Universitaire de Montréal, 3840 St-Urbain St, Office 2-420, Montreal, Quebec, Canada H2W 1T8 (E-mail: lm.stevens@videotron.ca).

$0022-5223 / \$ 36.00$

Copyright (C) 2012 by The American Association for Thoracic Surgery

doi:10.1016/j.jtcvs.2012.03.006
}

industries as an approach to stimulate productivity and, in hazardous domains, as an approach to accident reduction. ${ }^{1}$ Outside of anesthesia, ${ }^{2-4}$ there have been few attempts to focus on the process of improving patient safety in the operating theater. ${ }^{5-7}$ Some recent efforts in cardiac surgery highlight the increasing interest. ${ }^{8,9}$

For the operating room environment, realistic simulation offers a potential advantage for motivating a demanding audience to learn about teamwork principles and to alter their behaviors, both intended to reduce the risk of adverse events. Recently, the Controlled Risk Insurance Company (CRICO), the patient safety and medical professional malpractice liability company owned by and serving the Harvard medical community, has supported high realism simulation for adverse outcome prevention in anesthesia and obstetrics. ${ }^{10}$ Perceiving a positive claims experience in anesthesia, the company extended support of a simulation-based educational program to create a curriculum for educating general surgery teams in crisis resource management (CRM) ${ }^{5-7}$ That pilot program was an illustration of a procedural and mannequin simulator for this application. With further funding from CRICO, we developed a similar program specifically for experienced cardiac surgery teams, which is the basis for this study. 


\section{Abbreviations and Acronyms \\ $\mathrm{CRICO}=$ Controlled Risk Insurance Company \\ $\mathrm{CRM}=$ crisis resource management}

Others have reported the successful application of simulation-based learning for the technical and behavioral aspects of cardiac surgery to trainees where a single trainee was exposed to specific technical tasks or complex interaction with 1 or 2 expert actors/educators (surgeon, anesthesiologist, perfusionist) for crisis simulation or cardiopulmonary bypass management. ${ }^{4,11,12}$

The primary study intent was to test the feasibility of developing and implementing a robust educational program for CRM and especially communication for the cardiac surgical environment. It was hypothesized that a program using realistic simulation and interactive workshop would lead to improved patient safety and increased job satisfaction. The objectives of this study were as follows (1) to create crisis scenarios that occur in the cardiac surgical operating room or intensive care unit; (2) for each of these scenarios, to create documentation of ideal treatment responses and a discussion of common inaccurate responses; (3) to develop scenarios for simulation-based education in which cardiac surgical teams work in a realistic environment to optimize their interpersonal communication and team response; (4) to measure the effect of simulationbased crisis management education via caregiver pretraining and posttraining questionnaires and via posteducation interviews regarding all 3 components of the crisis management process: communication and data gathering, rapid arrival at a diagnosis, and appropriate team response; and (5) to develop an interactive workshop to share with everyone what was learned at the simulation and discuss strategies to improve teamwork and patient care. This pilot study was designed to ascertain via qualitative assessments which aspects of the intervention were effective or ineffective, how well the intervention was accepted by the participants, and to assess their perceptions of changes in teamwork and communication behaviors. To the best of our knowledge, this is the first report of a comprehensive program designed to train complete, experienced cardiac surgical teams in the management of crises situations using high realism simulation and/or interactive whole-unit workshop.

\section{METHODS}

The project was first proposed to CRICO for funding in 2006 and approved after a resubmission in 2007. Approval for this study was obtained from the Partner's Institutional Review Board in May 2007. Participants for this study were recruited among actively working cardiac surgery operating room team personnel including members of the following professions: cardiac surgeon and surgical physician assistant, cardiac anesthesiologist, perfusionist, cardiac operating room nurse, and cardiac anesthesia nurse.

\section{Clinical Scenarios}

Two acute crisis scenarios were developed for cardiac surgery on the basis of earlier versions used in other courses. A summary description of the situation, expected actions, and required decisions of the team and actors playing various roles is given in Table 1. Scenarios were designed on the basis of issues identified in the analysis of "near misses" in cardiac surgery. ${ }^{13}$ Scenarios were planned to engage all participants with various surgical, anesthesia, perfusion, and nursing issues. The scenarios provided a basis for the participants to discuss information sharing and the other elements of CRM according to the principles and curriculum for similar courses conducted at the Center for Medical Simulation (Cambridge, Mass; www.harvardmedsim.org), a high realism simulation facility that had been conducting similar programs since 1994 (Table 2). More specifically, the scenarios were designed to make the participants (1) aware of the types of events that occur in the operating room that potentially threaten patient safety and illustrate the need for teamwork to ensure effective event management and (2) allow them to actually practice strategies to prevent or mitigate the effects of these events in the future.

\section{Simulation Education}

We recruited a convenience sample of 5 complete, experienced cardiac surgical teams from the pool of all clinicians working in the cardiac surgical program. A core team included 1 attending cardiac surgeon, 1 cardiac anesthesiologist, 1 perfusionist, 1 or more cardiac operating room nurses, and 1 cardiac anesthesia nurse. Creation of simulation teams was based on simplicity of scheduling those who agreed to participate, according to their response at the first online survey (see below). To the extent possible, participants were assigned to sessions with others with whom they did not routinely work.

Each of the 5 teams participated in an approximately 4-hour teamwork education exercise conducted at the Center for Medical Simulation. Each session included the 2 cardiac surgery-specific simulation scenarios. Immediately after each scenario, a debriefing session was conducted using the approach of "debriefing with good judgment," 14 facilitated by an experienced instructor (D.B.R.). The participants discussed their reactions to what they had experienced, and using video of the event, discussed the team and individual performances. After the first scenario, an interactive, didactic presentation on teamwork behaviors based on principles of CRM was presented. The participants were encouraged to take part actively in the debriefings.

In addition to discussion of team and individual performance, the facilitators elicited from the team members their opinion of the set of information that each professional believes he or she needs from his or her colleagues during the courses of routine surgery and acute situations. Additionally, after completing the 2 scenarios and debriefings, the team was invited to critique and further develop 1 of 5 acute crisis scenario draft protocols: "cardiac laceration," "hypotension during cardiopulmonary bypass," "coagulopathy after cardiopulmonary bypass," "low cardiac output state after cardiopulmonary bypass," and "massive systemic air embolism." The goal of this exercise was to refine the protocols, facilitate a collaborative effort to reach agreement for the proper course of actions, identify the critical information that needs to be shared between team members, and characterize the specific role of every member of the team. Simulation-based education for these 5 teams was completed between October and December 2007 (Figure 1). Subsequently, general acute crisis management guidelines (Table 2) were disseminated to the entire cardiac operating room teams via e-mails, presentation at the interactive workshop (see below), and posters in the cardiac surgery operating room area.

\section{Whole-Unit Interactive Workshop in Communication and Teamwork Education}

As a follow-up to reinforce teamwork principles and to introduce them to those in the cardiac service who could not be accommodated in the 
TABLE 1. Acute crisis simulation scenarios for teamwork training in adult cardiac surgery

\begin{tabular}{|c|c|c|}
\hline & First simulation case & Second simulation case \\
\hline Scenarios & $\begin{array}{l}\text { Cardiac surgery team urgently called to resuscitate a patient } \\
\text { undergoing a CT scan for suspected stroke on postop day } 7 \\
\text { after an uneventful CABG surgery. The patient is halfway } \\
\text { through the CT scan and difficult to access. }\end{array}$ & $\begin{array}{l}\text { Cardiac surgery team called to help a thoracic surgeon in } \\
\text { a difficult case of tumor resection through a right } \\
\text { thoracotomy for suspected pheochromocytoma complicated } \\
\text { by profuse bleeding, hypovolemia, and myocardial ischemia. }\end{array}$ \\
\hline Expected actions & $\begin{array}{l}\text { - Resuscitate an unresponsive patient in the CT scan suite } \\
\text { using CPR principles } \\
\text { - Perform endotracheal intubation } \\
\text { - Differential diagnosis and treatment of PEA } \\
\text { - Treat presumptive cardiac tamponade in the CT scan suite by } \\
\text { using a pericardiostomy or thoracostomy kit or by } \\
\text { subxyphoid approach (simulator). }\end{array}$ & $\begin{array}{l}\text { Help stabilizing/resuscitating the patient in an unfamiliar } \\
\text { setting; the cardiac surgeon has to help isolating blood } \\
\text { vessels from the tumor model } \\
\text { - Confrontation with a blood bank problem } \\
\text { - Prepare to begin emergency CPB and manage the CPB pump } \\
\text { (pump simulator) } \\
\text { - Manage iatrogenic aortic dissection from the arterial } \\
\text { cannulation site. }\end{array}$ \\
\hline Required decisions & $\begin{array}{l}\text { - Which diagnostic imaging modality to use? } \\
\text { - Pertinence of an intra-aortic balloon pump? } \\
\text { - After presumptive diagnosis of cardiac tamponade, transfer } \\
\text { the unstable patient to the operating room? }\end{array}$ & $\begin{array}{l}\text { - Pertinence to go on CPB? } \\
\text { - What volume repletion strategy to use in the absence of } \\
\text { appropriately cross-matched blood (antibodies) } \\
\text { - Which cannulation site to use for CPB? }\end{array}$ \\
\hline Actors & $\begin{array}{l}\text { - Radiology technician: introduces the participants to the } \\
\text { patient } \\
\text { - Patient husband: a doctor in an unrelated field who criticizes } \\
\text { everything the team decides and requests to stay in the room } \\
\text { - Radiologist: misguides the team by reinforcing the belief that } \\
\text { the patient is presenting an anaphylactic reaction to the } \\
\text { contrast agent. }\end{array}$ & $\begin{array}{l}\text { Thoracic surgeon: requests help and guides the cardiac } \\
\text { surgeon toward CPB, if needed } \\
\text { - Thoracic anesthesiologist: becomes overwhelmed as the } \\
\text { hemorrhage increases } \\
\text { - Thoracic scrub nurse: helpful but unfamiliar with cardiac } \\
\text { surgery cases } \\
\text { - Circulating nurse: helps the perfusionists and others in the } \\
\text { case. }\end{array}$ \\
\hline
\end{tabular}

$C T$, Computed tomography; $C A B G$, coronary artery bypass graft; $C P R$, cardiopulmonary resuscitation; $P E A$, pulseless electrical activity; $C P B$, cardiopulmonary bypass.

simulation education sessions, a 4-hour interactive workshop was elaborated (Figure 1). The objectives of the workshop were to (1) review the learning during the simulation training and CRM principles, (2) teach the

\section{TABLE 2. Crew resource management principles}

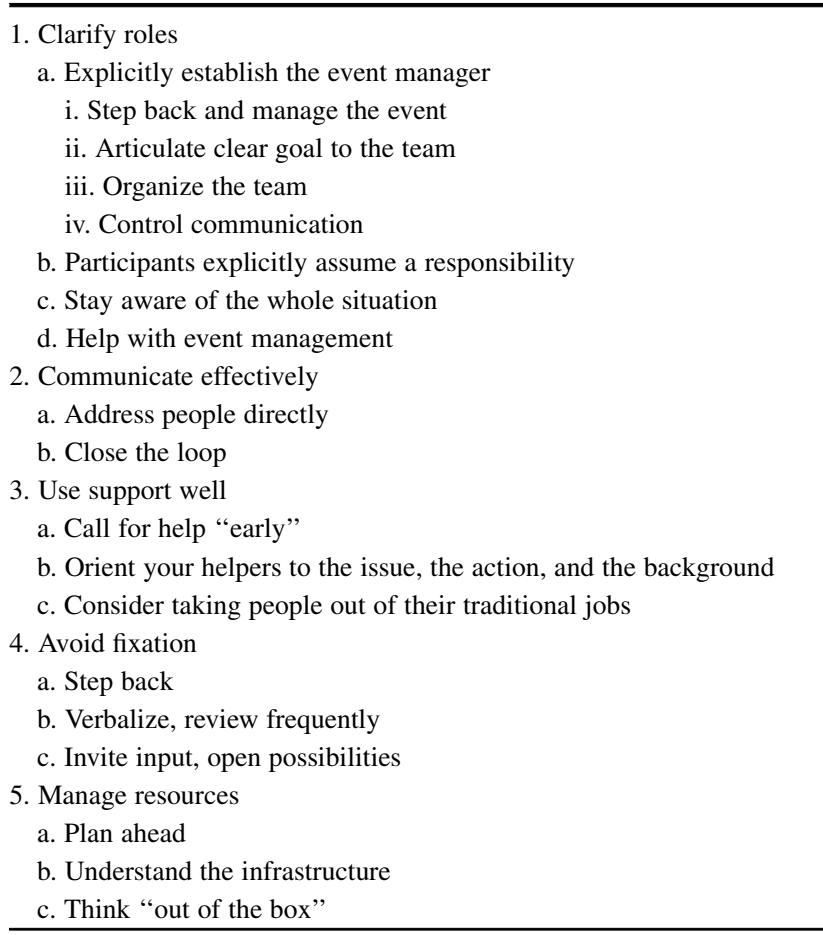

teamwork principles and their importance for optimizing patient outcomes, (3) review the survey results, and (4) via small group discussions, identify what survey issues were most in need of attention by the cardiac service and identify paths to achieve progress on these issues. All clinical staffs on the cardiac service were invited to participate. High attendance was ensured by holding the session during the regular 2-hour weekly educational block (7:00-9:00 AM) to which an additional 2 hours was added and for which the start of surgery was delayed.

\section{Study Measures}

Preintervention and 6-month postintervention surveys. A short survey tool was designed on the basis of elements of 2 surveys, 1 from a recent study of anesthesia safety climate throughout the Harvard Medical School affiliated hospitals ${ }^{15}$ and another used nationally for surgical teams. ${ }^{16}$ The emphasis was on teamwork, communication, and especially information sharing. Potential study participants were contacted directly by e-mail and were invited to complete a short, online teamwork environment survey (via www.surveymonkey.com). Each participant received a confidential identification number. These operating room teamwork climate surveys were sent to all Massachusetts General Hospital cardiac surgery room personnel, including participants and nonparticipants in the simulation-based education session or interactive workshop (Figure 1).

Immediate posteducation and postworkshop questionnaires. At the end of the simulation-based educational session and interactive workshop, all participants were requested to complete a shor questionnaire to evaluate the experience and assess their teamwork effectiveness, especially communication strategies and processes.

Interviews. As an adjunct to and extension of the 6-month postintervention survey, participants in the simulation-based education sessions were interviewed by 1 or 2 of the study investigators (J.B.C., L.M.S., 
TIMELINE

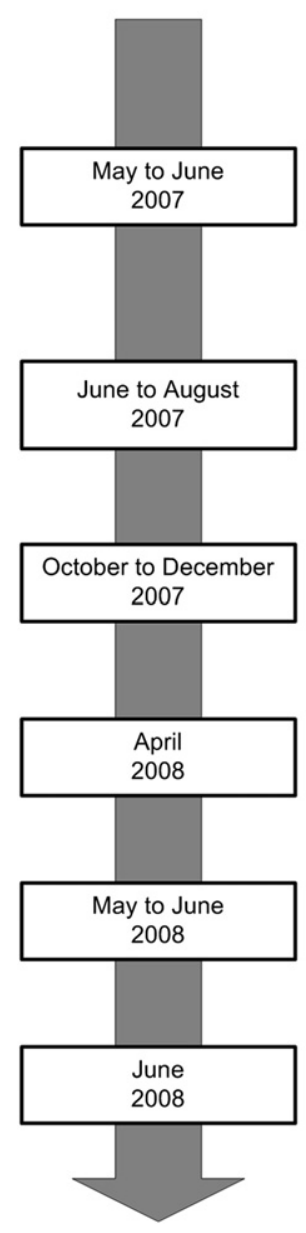

INTERVENTIONS AND STUDY MEASURES

NUMBER OF

PARTICIPANTS

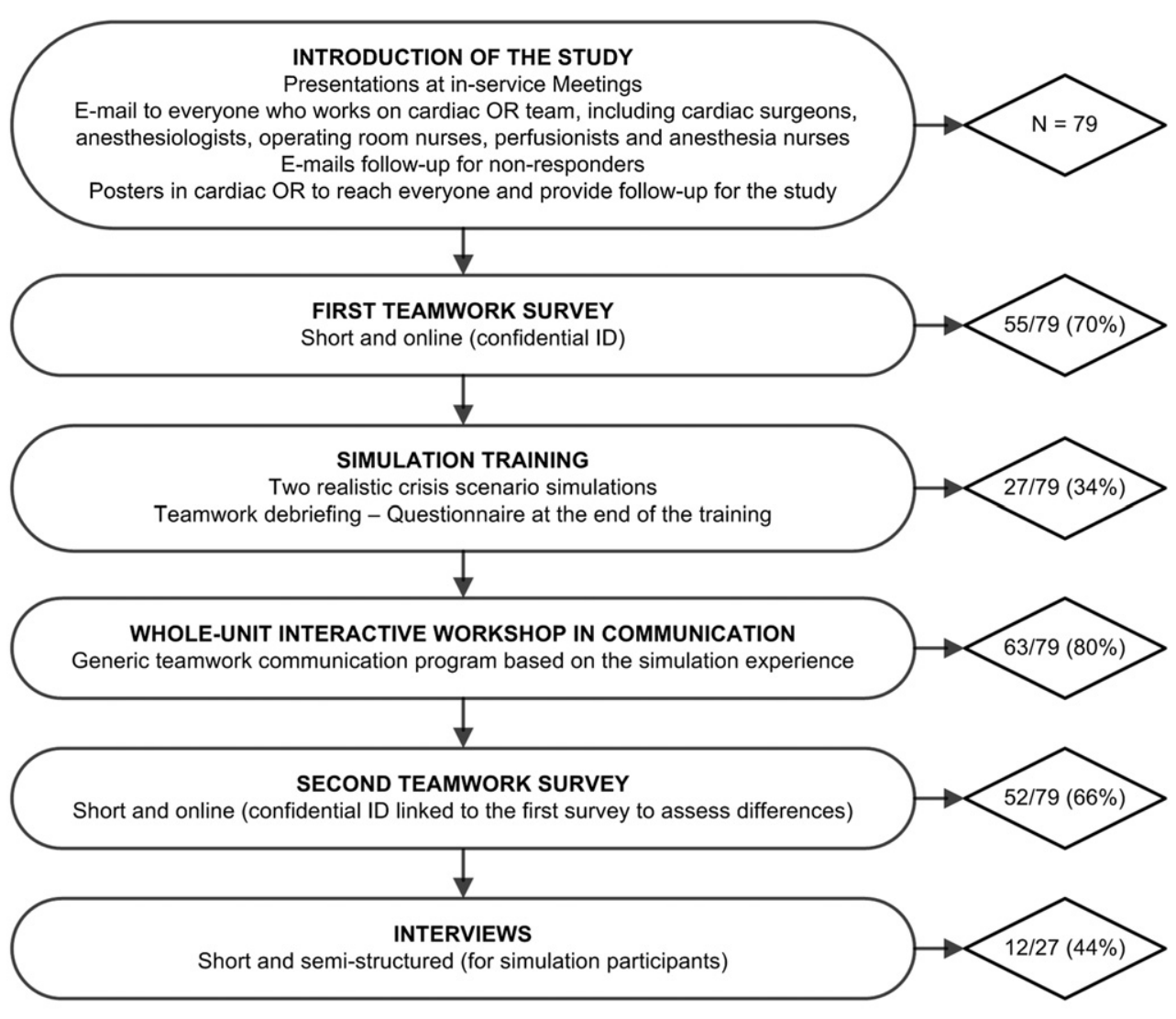

FIGURE 1. Timeline of the study. $O R$, Operating room; $I D$, identification.

and/or A.S.F.). The semistructured interview sought to obtain qualitative data about their attitudes regarding the effectiveness of the program and to solicit suggestions for improvement. Five interviews of 45 minutes to 1 hour were conducted (Figure 1). Each interview included only 1 of the clinical professions, with a convenience sample of representatives. The interviews were audio recorded and a summary transcription made of each. Given the relatively small number of total hours of interviews, the investigators analyzed the data by manually summarizing comments into intuitive categories with particular emphasis on examples of behaviors that had changed or remained the same and perceptions of the overall impact of the program on individuals.

\section{Statistical Methods}

We assessed the overall impact of the teamwork simulation-based education for all personnel involved or not in the simulation or workshop through their responses to the 2 surveys, questionnaires, and interviews. Data are expressed as number (percentage), mean \pm standard deviation, or $95 \%$ confidence interval. Mixed-effects ordinal logistic regression models were used to account for the correlation between repeated surveys measures in the same individual and were calculated using the NLMIXED procedure in SAS 9.1 software (SAS Institute, Inc, Cary, NC). Similar models were built for the whole group and for each of the 5 professional groups. Owing to small sample size in each professional group and of those who underwent the simulation-based educational program, we were not able to assess directly differences between the professional groups' answers or differences between those who participated in the simulationbased educational program or not. We consider values of $P<.05$ to be statistically significant but, given the small sample size, report results that tend toward significance for $P$ values of $<.10$.

\section{RESULTS}

Thirty-six $(65 \%)$ of the 55 respondents to the survey volunteered for the simulation exercise from which 27 were selected and divided into 5 complete, experienced cardiac surgery teams. The realism of the acute crisis simulation scenarios gradually improved; most participants rated both the simulation and whole-unit workshop as very good or excellent (Figure 2, A). Participants particularly appreciated the debriefing with video playback and were able to discuss critical elements of teamwork in a safe environment. Interestingly, 1 team experienced an unscripted drug error in which heparin was not provided as it should have been to the simulated patient. The group thoroughly assessed and discussed the communication chain disruption that led to this preventable incident and were "glad it 

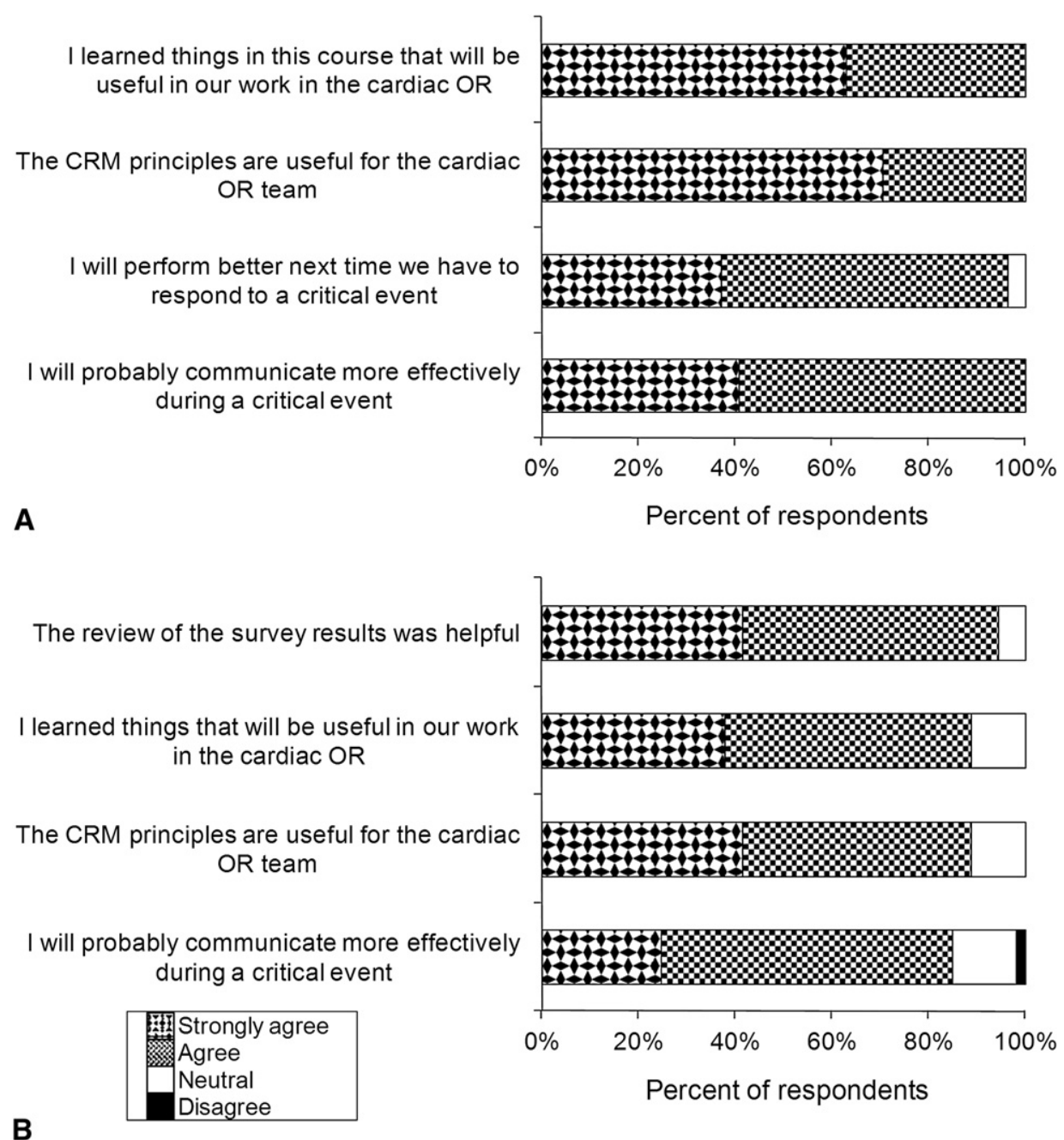

FIGURE 2. Selected questionnaire results for (A) the simulation training and (B) the whole-unit interactive workshop. OR, Operating room; CRM, crisis resource management.

happened here" inasmuch as it could have happened in real life. We observed that team communication improved demonstrably in the second simulation scenario compared with the first. Everyone addressed the issues noted at the debriefing of the first simulation scenario and the surgeon stepped back to assess the whole situation and coordinate the required actions of the other team members, in close relationship with the anesthesiologist. Also, team members addressed their colleagues by their names and closed the loop. Repeat simulation education was recommended every 6 months, 1 year, or 2 years by $26 \%, 56 \%$, and $19 \%$ of the participants, respectively.

Sixty-three $(80 \%)$ participants of the total of 79 invited attended the interactive workshop. During the workshop, the teams identified 2 areas of highest priority: encouraging speaking up about critical information and sharing information between professions during procedures. They also stressed the importance of briefings, early communication of surgical plan, knowing members of the team, and continued simulation for practice. Fifty-seven percent of participants in the workshop said they would volunteer to help implement the ideas created at the interactive workshop. The evaluations of the educational sessions were almost uniformly positive (Figure $2, B$ ). A repeat of the interactive workshop was recommended every 6 months, 1 year, or 2 years by $36 \%, 58 \%$, and $6 \%$ of the participants, respectively.

The first and second surveys were completed by $70 \%$ $(55 / 79)$ and $66 \%(52 / 79)$ of the cardiac surgery operating room members. In both surveys, participants indicated that they were generally not receiving the information they needed from other team members while believing that they were consistently providing adequate information to others. Only 1 aspect of team communication improved in the 1-year interval between the 2 surveys (the concept of all operating personnel working as a team; $P=.028$ ). Three other elements trended toward improvement although the change was not statistically significant (getting 


\section{Pre and post intervention safety climate surveys for cardiac surgery operating room (OR)}

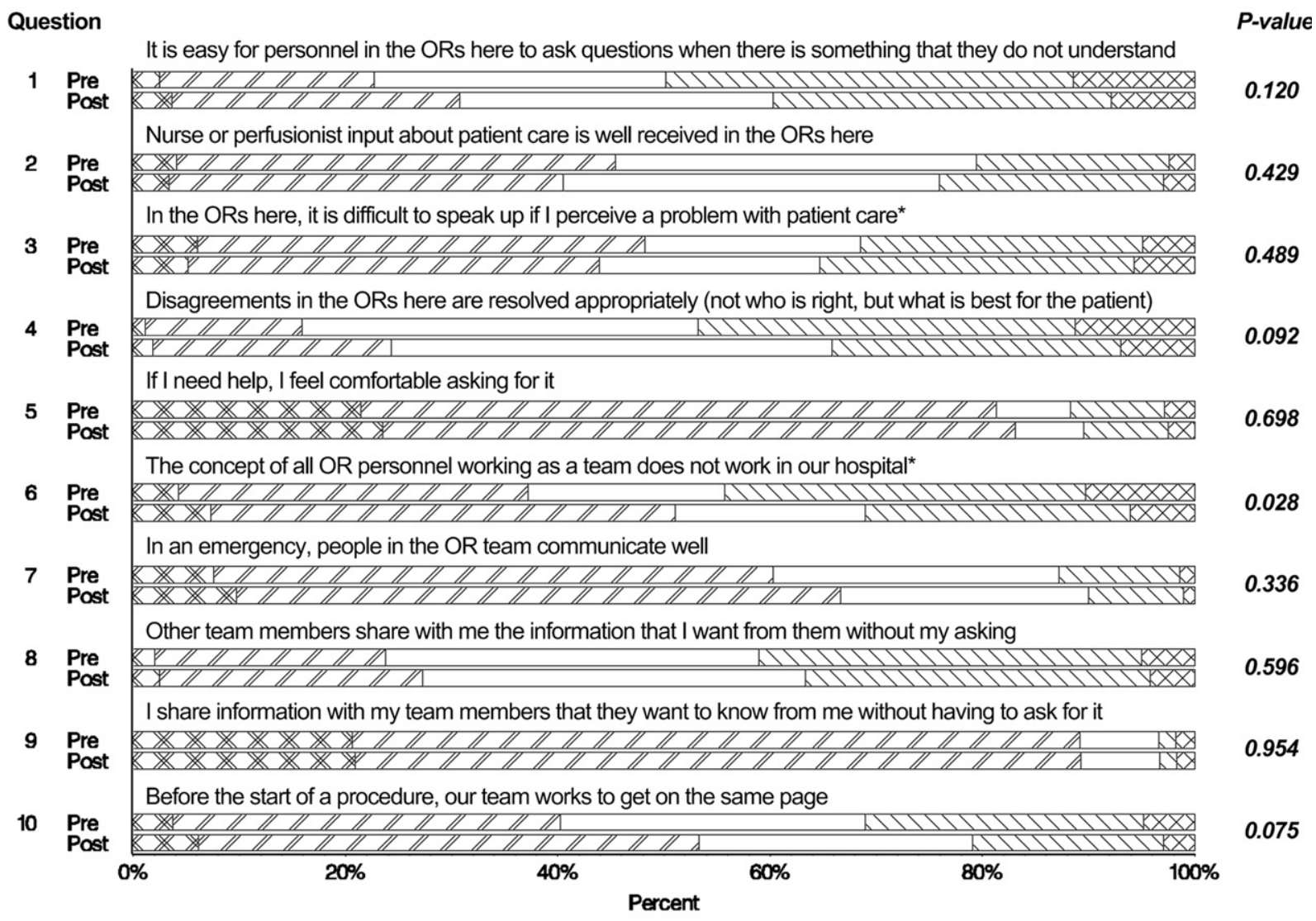

\begin{tabular}{|c|c|c|c|c|}
\hline$\triangle \mathbb{X}$ Strongly Agree & ए// Agree & Neutral & M.1. Disagree & $\bowtie$ Strongly Disagree \\
\hline
\end{tabular}

FIGURE 3. Results of the preintervention and postintervention surveys. Mixed-effects ordinal logistic regression models were used to account for the correlation between repeated surveys measures in the same individual, and $P$ values assess whether there has been a significant change between survey results. $O R$, Operating room.

on the same page before the start of a procedure $[P=.075]$; appropriate resolution of disagreements in the operating room $[P=.092]$; and asking questions when there is something that is not understood $[P=.12]$ ) (Figure 3 ).

Twelve participants of the simulation-based education sessions participated in 1 of the structured interviews, including 1 anesthesiologist, 2 cardiac anesthesia nurses, 2 cardiac surgeons, 3 operating room nurses, and 4 perfusionists. Interviewees overall had a consistent, very highly positive perception of both the simulation session and the all-service meeting. Every interviewee believed that this kind of training should continue because they perceived it as having a positive overall impact for the service and for patient care. About half of those interviewed gave examples of how they had changed their own teamwork behaviors directly as a result if the training; the most common examples were being able to speak up more readily, communicating more clearly by addressing team members by their names, and paying more attention to "closing the loop" in verbal communications. One participant reported a new routine of conducting a briefing at the beginning of surgery while taking the time to listen to other team members. This was confirmed by other participants who believed this was the "right way to go." Another noticed "many mini-crises where the heat has been turned down more" after the simulation experience and interactive workshop. Others reported averting a potential complication by "speaking up more freely" in an instance where it was unclear whether the team was aware of important information. There were several comments about the training as a "bonding" experience and the importance of this kind of social interaction for the entire team. Interviewees were learning from each other during the interview and reflecting on what they learned in the trainings. 


\section{DISCUSSION}

The goal of surgical teams is to provide the most successful, safest, highest quality, and most efficient procedural experience for every patient. The literature suggests that high-performance teams and organizations are more likely to perform well. ${ }^{1}$ Such teams have common, expressed goals and complementary skills, are mutually accountable for results, depend on each other in pursuit of the goals, demonstrate candor and mutual respect in their interactions, and have clear processes to communicate thoughts and actions. High-functioning teams are also more likely to successfully adopt new technology. Unfortunately, these characteristics are still infrequently taught explicitly or consistently in health care environments. In the current educational model, trainees or "junior" caregivers learn about relatively infrequent crises in an apprenticeship model. Similarly, unlike teams in other high-risk industries, cardiac surgical teams do not routinely practice critical events to ensure their readiness to do so. We have demonstrated in this pilot study that it is possible to develop engaging scenarios for the training of entire, experienced cardiac surgical teams by practicing specific crises and working toward developing more effective teamwork in general.

High realism simulation is increasingly used throughout health care for clinical and behavioral skills education. ${ }^{411,12,16-20}$ Both the Advanced Trauma Life Support (ATLS, American College of Surgeons) and the Advanced Cardiac Life Support courses (ACLS, American Heart Institute) rely on simulation as part of their educational and testing modalities. Among the many different approaches to teamwork education, the use of simulation is being applied increasingly., 2,4,11,12,21 This special expertise in crisis management and teamwork is based on aviation's Crew Resource Management model as refined for health care. ${ }^{7,22,23}$ It was first applied to health care in anesthesia under the term Anesthesia Crisis Resource Management (ACRM) education. ${ }^{1,7}$ Although this approach has not been shown definitively to improve patient outcomes, participants believe that it improves their performance during critical patient care events. ${ }^{3}$ One group was able to demonstrate in a single randomized clinical trial the superiority of simulation-based learning compared with interactive seminars in the performance of a complex task (cardiopulmonary bypass weaning) leading to improved performance in patient care for senior anesthesiology trainees. ${ }^{4}$ Our study was not designed to compare a simulation-based approach to an interactive workshop, but to use these 2 didactic approaches in a common goal of improving experienced cardiac surgery teams' communication behaviors.

In this study, the participants perceived that this type of training was important to improve their skills in various aspects of teamwork. Although nonsimulation-based educational methods can improve teamwork performance, ${ }^{22}$ we believe that realistic simulation offers a great advantage for motivating a demanding audience such as in cardiac surgery to learn about teamwork principles and to alter their behaviors toward reducing the risk of adverse events. There is also evidence that teamwork skills can be taught to some health care teams through a primarily didactic approach such as TeamSTEPPS (Team Strategies and Tools to Enhance Performance and Patient Safety). ${ }^{24} \mathrm{We}$ chose a simulation approach based on our belief that it would effectively engage the cardiac surgery team, as is used in aviation, and would motivate the behavioral changes that are so important for improving patient safety. For many participants, the current study (simulation and workshop) was an "eye-opening" experience that helped them to see imperfections in their practice, on which points their teamwork could be improved, and the rationale for participating in this educational experience.

Several trends toward an improvement in operating room member teamwork and satisfaction were noted. The concept of debriefing as a process of maintaining a common understanding about the operative plan was embraced by almost all participants in the program. However, as experience has shown in aviation, teamwork education via simulations or workshops needs to be repeated to ensure that the behavioral changes are maintained. Efficient debriefing could also motivate teams to do the kind of debriefings after procedures that are encouraged by the World Health Organization's Surgical Checklist. ${ }^{25}$ Simulation sessions could also be designed to motivate and teach a process of rebriefing during the procedure, for example, formally or informally reviewing current status and trajectory of the procedure. As a result of the very positive reception to this program by almost everyone in the cardiac service, in the year after this study the simulations and all-service meeting were repeated and other efforts added. That effort was purely as a quality improvement program, not as a research study. Thus, those details and findings are not reported here. Furthermore, we were officially informed that the cardiothoracic surgeons completing this simulationbased teamwork training will receive a reduction in their malpractice premium along with other surgeons in a program under consideration by CRICO, the patient safety and medical professional liability company owned by and serving the Harvard medical community.

\section{CONCLUSIONS}

In this study, we demonstrated that the development and application of a structured program of teamwork education in cardiac surgery is feasible and that positive changes in behavior can be measured through surveys and interviews. Teamwork education requires ongoing commitment and leadership engagement. Simulation exercises or interactive 
workshops should be repeated frequently for sustained improvement in patient care. In the current financial environment, support of such programs may be challenging. However, we believe they should be prioritized given that improved patient safety is the central goal of this approach.

We thank the simulation project team leaders for operating room nurses, Joanne Thistle and Lisa Morrissey, perfusionists, Stephen Snow, and cardiac anesthesia nurses, Barbara Hill, for their enthusiast participation in the project, many helpful suggestions, and unswerving support. Special thanks to Karen E. Lynch, $\mathrm{RN}$, for her helpful insights. We also thank the members of the cardiac surgical service who participated in these training sessions and interviewees for their interest in developing the program.

\section{References}

1. Salas E, Wilson KA, Burke CS, Wightman DC. Does crew resource management training work? An update, an extension, and some critical needs. Hum Factors. 2006;48:392-412.

2. Holzman RS, Cooper JB, Gaba DM, Philip JH, Small SD, Feinstein D. Anesthesia crisis resource management: real-life simulation training in operating room crises. J Clin Anesth. 1995;7:675-87.

3. Blum RH, Raemer DB, Carroll JS, Sunder N, Felstein DM, Cooper JB. Crisis resource management training for an anaesthesia faculty: a new approach to continuing education. Med Educ. 2004;38:45-55.

4. Bruppacher HR, Alam SK, LeBlanc VR, Latter D, Naik VN, Savoldelli GL, et al. Simulation-based training improves physicians' performance in patient care in high-stakes clinical setting of cardiac surgery. Anesthesiology. 2010;112:985-92.

5. Blum RH, Raemer DB, Carroll JS, Dufresne RL, Cooper JB. A method for measuring the effectiveness of simulation-based team training for improving communication skills. Anesth Analg. 2005;100:1375-80.

6. Cooper JB, Singer SJ, Hayes J, Sales M, Vogt JW, Raemer D, et al. Design and evaluation of simulation scenarios for a program introducing patient safety, teamwork, safety leadership, and simulation to healthcare leaders and managers. Simul Healthc. 2011;6:231-8.

7. Gaba DM, Howard SK, Fish KJ, Smith B, Sowb Y. Simulation-based training in anesthesia crisis ressource management (ACRM): a decade of experience. Simul Gaming. 2001;32:175-93.

8. Carthey J, de Leval M, Wright D, Farewell V, Reason J. Behavioural markers of surgical excellence. Safety Sci. 2003;41:409-25.

9. de Leval MR, Carthey J, Wright DJ, Farewell VT, Reason JT. Human factors and cardiac surgery: a multicenter study. J Thorac Cardiovasc Surg. 2000;119(4 Pt 1):661-72.
10. Hanscom R. Medical simulation from an insurer's perspective. Acad Emerg Med. 2008;15:984-7.

11. Burkhart HM, Riley JB, Hendrickson SE, Glenn GF, Lynch JJ, Arnold JJ, et al. The successful application of simulation-based training in thoracic surgery residency. J Thorac Cardiovasc Surg. 2010;139:707-12.

12. Hicks GL Jr, Gangemi J, Angona RE Jr, Ramphal PS, Feins RH, Fann JI. Cardiopulmonary bypass simulation at the Boot Camp. J Thorac Cardiovasc Surg. 2011;141:284-92.

13. Wong DR, Vander Salm TJ, Ali IS, Agnihotri AK, Bohmer RM, Torchiana DF. Prospective assessment of intraoperative precursor events during cardiac surgery. Eur J Cardiothorac Surg. 2006;29:447-55.

14. Rudolph JW, Simon R, Dufresne RL, Raemer DB. There's no such thing as "nonjudgmental" debriefing: a theory and method for debriefing with good judgment. Simul Healthc. 2006;1:49-55.

15. Cooper JB, Blum RH, Carroll JS, Dershwitz M, Feinstein DM, Gaba DM, et al. Differences in safety climate among hospital anesthesia departments and the effect of a realistic simulation-based training program. Anesth Analg. 2008;106:574-84.

16. Sexton JB, Makary MA, Tersigni AR, Pryor D, Hendrich A, Thomas EJ, et al. Teamwork in the operating room: frontline perspectives among hospitals and operating room personnel. Anesthesiology. 2006;105:877-84.

17. Bond WF, Spillane L. The use of simulation for emergency medicine resident assessment. Acad Emerg Med. 2002;9:1295-9.

18. Gallagher AG, Cates CU. Virtual reality training for the operating room and cardiac catheterisation laboratory. Lancet. 2004;364:1538-40.

19. Seymour NE, Gallagher AG, Roman SA, O'Brien MK, Bansal VK, Andersen DK, et al. Virtual reality training improves operating room performance: results of a randomized, double-blinded study. Ann Surg. 2002;236:458-63.

20. Sica GT, Barron DM, Blum R, Frenna TH, Raemer DB. Computerized realistic simulation: a teaching module for crisis management in radiology. AJR Am J Roentgenol. 1999;172:301-4.

21. Gardner R, Walzer TB, Simon R, Raemer DB. Obstetric simulation as a risk control strategy: course design and evaluation. Simul Healthc. 2008;3:119-27.

22. Morey JC, Simon R, Jay GD, Wears RL, Salisbury M, Dukes KA, et al. Error reduction and performance improvement in the emergency department through formal teamwork training: evaluation results of the MedTeams project. Health Serv Res. 2002;37:1553-81.

23. Baker DP, Salas E, King H, Battles J, Barach P. The role of teamwork in the professional education of physicians: current status and assessment recommendations. Jt Comm J Qual Patient Saf. 2005;31:185-202.

24. King HB, Battles J, Baker DP, et al. TeamSTEPPS ${ }^{\mathrm{TM}}$ : team strategies and tools to enhance performance and patient safety. In: Henriksen K, Battles JB, Keyes MA, et al, eds. Advances in patient safety: new directions and alternative approaches. Vol. 3. Performance and tools. Rockville, MD: Agency for Healthcare Research and Quality (US); 2008. Available at: http://www.ncbi.nlm.nih.gov/books/ NBK43686/.

25. Haynes AB, Weiser TG, Berry WR, Lipsitz SR, Breizat AH, Dellinger EP, et al. A surgical safety checklist to reduce morbidity and mortality in a global population. N Engl J Med. 2009;360:491-9. 